\title{
Comparison of KRAS and EGFR gene status between primary non-small cell lung cancer and local lymph node metastases: implications for clinical practice
}

\author{
Leina Sun ${ }^{1}$, Qiang Zhang², Huanling Luan', Zhongli Zhan', Changli Wang ${ }^{2}$, Baocun Sun ${ }^{1,3,4^{*}}$
}

\begin{abstract}
Background: Epidermal growth factor receptor tyrosine kinase inhibitors (EGFR-TKI) have been widely used for the treatment of non-small cell lung cancer (NSCLC). KRAS and EGFR somatic mutations in NSCLC may predict resistance and responsiveness to TKI, respectively. Nevertheless, most research to date has been conducted on samples from primary tumors. For many patients with advanced disease, their samples can only be obtained from metastases for test. The molecular characteristics of metastasized tumors may be different from those of primary tumors.

Materials and methods: Mutation status of KRAS and EGFR between primary tumors and local lymph node metastases of 80 Chinese patients with NSCLC were analyzed by direct sequencing. Five of them were given gefitinib as neoadjunvant treatment after the EGFR-TKI sensitive mutations were detected in their biopsies of mediastinal lymph nodes metastases. McNemar's test was used to compare the EGFR and KRAS mutation status between primary tumors and corresponding local lymph node metastases. Data evaluation was carried out with SPSS_13.0 statistical software.
\end{abstract}

Results: Among the 160 samples, one primary tumor and seven metastases were identified with KRAS mutations and 21 primary tumors and 26 metastases were found to have EGFR mutations. KRAS and EGFR mutation status was different between primary tumors and corresponding metastases in 6 (7.5\%) and 7 (8.75\%) patients, respectively. One patient with no TKI sensitive mutations detected in the primary tumor showed disease progression.

Conclusion: Our results suggest that a considerable proportion of NSCLC in Chinese population showed discrepancy in KRAS and EGFR mutation status between primary tumors and corresponding metastases. This observation may have important implication for the use of targeted TKI therapy in the treatment of NSCLC patients.

\section{Introduction}

Lung cancer is one of the leading causes of cancerrelated mortality both in China and throughout the world $[1,2]$. Non-small cell lung cancer (NSCLC) accounts for $75-80 \%$ of all lung cancer [3]. Standard therapeutic strategies such as surgery, chemotherapy, or

\footnotetext{
* Correspondence: baocunsun@gmail.com

'Department of Pathology, Tianjin Medical University Cancer Institute and Hospital; Tianjin 300060, China

Full list of author information is available at the end of the article
}

radiotherapy have reached a plateau [1]. Significant advances in the research of the biology and molecular mechanisms of cancer have allowed the development of new molecularly targeted agents for the treatment of NSCLC [4-8]. One such target is the epidermal growth factor receptor (EGFR), a $170-\mathrm{kDa}$ trans-membrane glycoprotein and member of erbB family. Small molecule tyrosine kinase inhibitors (TKI), such as gefitinib and erlotinib, disrupt EGFR kinase activity by binding the adenosine triphosphate pocket within the catalytic

\section{Ciomed Central}


region of the tyrosine kinase domain [9]. Currently, both gefitinib and erlotinib are used for treatment of patients with advanced NSCLC. TKI clinical trials have shown that these agents have dramatic effect on the subset of NSCLC patients with somatic mutations in the tyrosine kinase domain of the EGFR gene, whereas the presence of KRAS mutations seems to be correlated with primary resistance to these agents [10-15]. So it is necessary to identify the mutation status of KRAS and EGFR for selection of patients who are more likely to benefit from TKI. Although almost 70\% of patients with NSCLC present with locally advanced or metastatic disease at the time of diagnosis [16,17], KRAS and EGFR mutation status is most commonly assessed only in the primary tumor tissue based on the assumption that primary and metastases are pathologically concordant. However, it has been known that lung cancers are often heterogeneous at the molecular level even within the same tumor and many key molecular alterations may occur during metastatic progression [18-20]. It is still unclear whether KRAS and EGFR mutation status in primary tumors is reflected in their corresponding metastases in Chinese patients with NSCLC, although several recent relevant studies in western countries have been performed and published [21-26].

In the present study, we investigate KRAS and EGFR mutation status using PCR-based sequencing analyses in 80 primary tumor samples and their corresponding local lymph node metastases from Chinese patients with NSCLC. The goal is to determine whether KRAS and EGFR mutation profile is stable during the metastatic progress and to investigate the clinical usefulness of mutational analyses in primary tumor versus in metastases for planning EGFR-targeted therapies for the treatment of patients with NSCLC.

\section{Materials and methods}

\section{Patients and samples}

Patients were selected from a pathological database of lung cancer cases undergoing curative resection for excision of primary tumor and the corresponding lymph nodes metastases at the Pathology Department of Tianjin Medical University Cancer Hospital from March 2009 to September 2009. Only patients with paraffin embedded tissues from surgically resected primary lung cancers and lung cancer-related local lymph node metastatic samples with histologically confirmed NSCLC were included. Patients who had been exposed to TKI before surgical treatment were excluded from this study. In each case, hematoxylin and eosin-stained sections of formalin-fixed paraffinembedded tissue of primary tumor and corresponding synchronous lymph node metastases were reviewed by two pathologists to identify neoplastic areas and the amount of tumor cells in order to ensure that they contained more than $70 \%$ of tumor components for DNA extraction and mutation analysis. Tissue blocks were macro-dissected using a safety blade when samples were less than $70 \%$ of tumor cells. Primary tumor and lymph node specimens were obtained from all patients by surgical resection of primary tumors with lymph nodes dissection according to prevailing surgical standards. Consequently, 80 pairs of primary tumors and the corresponding lymph nodes metastases were analyzed. All samples were from patients of Chinese origin with NSCLC. The characteristics of the included patients were shown in Table 1 .

The inclusive criteria for selecting patients to receive gefitinib as neoadjunvant therapy were as follows: (1) NSCLC verified by cytology or histology; (2) age 18 to 70 years; (3) NSCLC with stage IIIA or IIIB and the tumors were confined in homolateral thoracic cavity; (4) patients without metastases in contralateral mediastinal lymph node; (5) patients who have never received treatment; (6) patients who could tolerate the surgery; (7) patients who were willing to receive preoperative target therapy. The exclusive criteria were: (1) without definite diagnosis; (2) age $\geq 70$ years; (3) NSCLC with N3 or distant metastases; (4) small cell lung cancer; (5) patients who have been treated before; (6) patients who were unable to tolerate radical surgery. The local ethics committee granted approval, and written informed consent was obtained from each patient.

\section{DNA extraction}

Thirty mg of frozen tissue was shredded by scissors. The E.Z.N.ATM Tissue DNA Kit (purchased by OMEGA) was used to extract genomic DNA. Quality and concentration of the DNA samples were examined by Nano Drop (Thermo ${ }^{\mathrm{TM}}$ ). Genomic DNA was then diluted to a working concentration of 5-10 ng/ul.

Table 1 Patients' Characteristics ( $\mathbf{N}=\mathbf{8 0}$ )

\begin{tabular}{ll}
\hline Characteristics & Patient Number (\%) \\
\hline $\begin{array}{l}\text { Age, mean (range) } \\
\text { Gender }\end{array}$ & $58(32-77)$ \\
$\quad$ Male & $50(62.5)$ \\
$\quad$ Female & $30(37.5)$ \\
Pathologic type & $39(48.75)$ \\
$\quad$ Adenocarcinoma & $31(38.75)$ \\
$\quad$ Squamous cell carcinoma & $6(7.5)$ \\
$\quad$ Adenosquamous carcinoma & $4(5)$ \\
$\quad$ Large cell carcinoma & \\
Smoking history & $49(61.25)$ \\
$\quad$ Ever & $31(38.75)$ \\
$\quad$ Never &
\end{tabular}




\section{PCR Amplification and sequencing}

The two codons of KRAS (12 and 13) and two exons of EGFR (19 and 21) were amplified by PCR using the following forward and reverse primers: exon 1 of KRAS: 5'AAAGGTACTGGTGGAGTATTTGATAGTG-3', 5 “ -TCATGAAAATGGTCAGAGAAACCT- 3 '; EGFR e x o n 1 9: 5 ' -AGCATGTGGCACCATCTCAC-3',5'GCAGGGTCTAGAGCAGAGCAG-3'; $E$ G $F R$ e $\mathrm{x}$ o n 2 1: 5 ' - C T G A A T T C G G A T G C A G A G C T T -3 ', 5 ' - C T A G T G G G A A G G C A G C C T G G T - 3. A total of $20 \mu$ l PCR reaction system included the following: $1 \mathrm{x}$ HotStarTaq buffer, $2.0 \mathrm{mM}$ $\mathrm{Mg} 2+, 0.2 \mathrm{mM}$ dNTP, $0.2 \mu \mathrm{M}$ of each primer, $1 \mathrm{U}$ HotStarTaq Polymerase (Qiagen), and 10ng DNA template. PCR reaction procedures were performed using 35 cycles of $15 \mathrm{sec}$ at $94^{\circ} \mathrm{C}, 30 \mathrm{sec}$ at $56^{\circ} \mathrm{C}, 1 \mathrm{~min}$ at $72^{\circ} \mathrm{C}$ and extension for $2 \mathrm{~min}$ at $72^{\circ} \mathrm{C}$. Sequencing reactions were performed on an ABI3700 genetic analyzer after PCR products were purified. Sequence variations were determined using Seqscape software (Applied Biosystems) with the KRAS and EGFR reference sequence (NM_004985 and NM_005228.3, National Center for Biotechnology Information).

In order to avoid contamination during PCR steps, gloves and lab coats were worn at all times when PCR is performed. Pipette tips with aerosol filters were used to prevent microdroplets being injected into the PCR mixture. DNA sample preparation was done in a separate room from the area where PCR reaction mixes were prepared. Additionally negative control was also included during PCR procedure.

\section{Drug administration}

Five patients received gefitinib as first-line treatment after being identified to harbor EGFR-TKI sensitive mutations in mediastinal lymph nodes metastases obtained by mediastinoscope. One tablet of gefitinib (250 mg) was taken once daily at about the same time. Patients continued the course uninterrupted until disease progression, intolerable toxicity or withdrawal of consent. All drugs were supplied by AstroZeneca.

\section{Assessment of response}

Baseline evaluation included medical history and physical examination, electrocardiogram, chest radiography, thorax CT scan and ultrasonography of the upper abdomen. Laboratory investigations included complete blood counts, urinalysis, renal function and liver function tests. Performance status was evaluated according to the Eastern Cooperative Oncology Group (ECOG) criteria. Patients were re-evaluated, using the same method at the end of the first and third months of therapy, and then every 3 months. Objective tumor response and its duration were assessed according to the RECIST criteria
[27], and all responses were confirmed $>28$ days after the initial assessment of response.

\section{Statistical analysis}

McNemar's test was used to compare the EGFR and $K R A S$ mutation status between primary tumors and corresponding local lymph node metastases. Two-sided $p$ values $<0.05$ were considered significant. Data evaluation was carried out with SPSS_13.0 statistical software.

\section{Results}

KRAS gene mutations in NSCLC primary tumors and corresponding local lymph node metastases

KRAS mutations were detected in one primary tumor and seven lymph node metastases (Table 2). All of them were point mutations: five in codon 12 (G12A, G12V, G12S), two in codon 13 (G13D). Only one patient carried the same KRAS mutation in both primary tumor and metastatic tumor (Table 2, case 31). Six samples had mutations in lymph node metastases but not in their corresponding primary tumor tissues (Table 2, case7 to case12). Two of the KRAS mutation-positive samples (Table 2, case 7 and case 8 ) also carried the L858R EGFR mutation. NSCLC samples harboring both $K R A S$ and EGFR mutations have rarely been reported previously. One sample had a KRAS mutation only in the metastases; the other one had KRAS mutations in both sites. The correlation between KRAS mutation and clinical parameters such as gender, smoke history and pathologic type was not statistically significant. Discordance in KRAS mutation status between primary tumors and lymph node metastases observed in six patients was found statistically significant (McNemar's test, $P=$ 0.0412 , Table 3$)$. The majority (6/7) of all cases with KRAS mutations were squamous cell lung cancers. The other one was an adenocarcinoma.

\section{EGFR gene mutations in NSCLC primary tumors and corresponding local lymph node metastases}

EGFR mutations were detected in twenty-one primary tumors and twenty-six lymph node metastases. The types and locations of the mutations in paired tumors were shown in Table 2. Thirteen cases of the in-frame deletions in exon 19 and eight cases of point mutation in exon 21 were found in the primary tumors. Twentysix cases with EGFR mutations in the lymph nodes included fourteen cases of the in-frame deletions in exon 19 and twelve cases of the point mutation in exon 21. All point mutations found in those samples were Leucin to Arginine at position 858 (L858R). The clinicopathologic characteristics that were significantly associated with EGFR mutations were gender, smoke history and pathologic type. Woman, non-smoker and adenocarcinoma showed a higher percentage of EGFR 
Table 2 Comparison of EGFR and KRAS status between primary and metastatic tumors in NSCLC patients

\begin{tabular}{|c|c|c|c|c|}
\hline \multirow[t]{2}{*}{ Case No. } & \multicolumn{2}{|c|}{ EGFR mutation status } & \multicolumn{2}{|c|}{ KRAS mutation status } \\
\hline & primary & metastasis & primary & metastasis \\
\hline 1 & E746-A750 & L747-T751 & wt & wt \\
\hline 2 & L747-P753insS & R748-P752 & wt & wt \\
\hline 3 & wt & L747-P753 & wt & wt \\
\hline 4 & wt & L858R & wt & wt \\
\hline 5 & wt & L858R & wt & wt \\
\hline 6 & wt & L858R & wt & wt \\
\hline 7 & wt & L858R & wt & G12V \\
\hline 8 & L858R & L858R & wt & G12A \\
\hline 9 & wt & wt & wt & G12V \\
\hline 10 & wt & wt & wt & G13D \\
\hline 11 & wt & wt & wt & G12S \\
\hline 12 & wt & wt & wt & G13D \\
\hline 13 & E746-A750 & E746-A750 & wt & wt \\
\hline 14 & E746-A750 & E746-A750 & wt & wt \\
\hline 15 & E746-A750 & E746-A750 & wt & wt \\
\hline 16 & E746-A750 & E746-A750 & wt & wt \\
\hline 17 & E746-A750 & E746-A750 & wt & wt \\
\hline 18 & E746-A750 & E746-A750 & wt & wt \\
\hline 19 & E746-A750 & E746-A750 & wt & wt \\
\hline 20 & L858R & L858R & wt & wt \\
\hline 21 & L858R & L858R & wt & wt \\
\hline 22 & L858R & L858R & wt & wt \\
\hline 23 & L858R & L858R & wt & wt \\
\hline 24 & L858R & L858R & wt & wt \\
\hline 25 & L858R & L858R & wt & wt \\
\hline 26 & L858R & L858R & wt & wt \\
\hline 27 & L747-S752,P753E & L747-S752,P753E & wt & wt \\
\hline 28 & E746-T751insV/A & E746-T751insV/A & wt & wt \\
\hline 29 & E747-S752insV & E747-S752insV & wt & wt \\
\hline 30 & I740-K745 & I740-K745 & wt & wt \\
\hline 31 & wt & wt & G12A & G12A \\
\hline 32 & wt & wt & wt & wt \\
\hline
\end{tabular}

Table 3 Combined analysis of EGFR and KRAS status in NSCLC patients

\begin{tabular}{lccccc}
\hline \multicolumn{5}{c}{ Primary/Metastatic tumor } \\
\hline & WT/WT & WT/MUT & MUT/WT & MUT/MUT & Discordance \\
\hline EGFR & 54 & 5 & 0 & $21^{*}$ & 7 case \\
\hline KRAS & 73 & 6 & 0 & 1 & 6 case \\
\hline * E746-A750/L747-T751; L747-P753insS/R748-P752. \\
Abbreviation: WT, wild type; MUT, mutational type.
\end{tabular}

mutations (60\%, 55\% and 48\%, respectively; $P<0.05)$. Discordant cases included five cases with no EGFR mutation in the primary tumors (Table 2, cases 3 to 7 ) and two cases with the metastases having a different EGFR mutation (Table 2, case 1 and case 2) (McNemar's test, $P=0.0736$, Table 3 ).

\section{Response to gefitinib as neoadjuvant treatment}

Five patients (Table 2, case 3 and cases 20 to 23) were given gefitinib as neoadjunvant treatment after the EGFR-TKI sensitive mutations were detected in their biopsies of mediastinal lymph nodes metastases by DNA direct sequencing. Of the five patients, three harbored delE746-A750 in exon 19 and the other two harbored L858R in exon 21. Four patients showed response to gefitinib and one experienced progressive disease. Among the four patients showing response to gefitinib, the size of both primary tumors and the mediastinal lymph nodes were found to shrink when examined by thorax CT scan (Figure 1). All four patients responded to gefitinib then received radical resection of the pulmonary carcinomas successfully after being evaluated to be suitable for surgery. Then their primary tumors harvested from surgery were examined for the EGFR mutations. We found that all four samples had the same mutations as those found in their mediastinal lymph nodes metastases. The patient who experienced progressive disease on gefitinib showed volume increase of the primary tumor and obvious hydrothorax, not a candidate for surgery according to NCCN Guidelines ${ }^{\mathrm{TM}}$ (Figure 2). With permission of this patient, we obtained his primary tumor tissue through ultrasound-guided aspiration in order to examine the gene mutation status. No mutations were detected in either the EGFR gene or the $K R A S$ gene in the primary tumor from this patient.

\section{Discussion}

NSCLC represents a major global health problem, but the introduction of a novel class of targeted anti-neoplastic agents, EGFR TKI, directed against EGFR has significantly changed the therapeutic options available for patients with NSCLC. Several studies have shown that activating EGFR mutations in exon 18, 19 and 21 are associated with a $75-95 \%$ objective response rate with EGFR TKI, whereas KRAS mutations are associated with a lack of sensitivity to these agents. However, of all patients with newly diagnosed NSCLC, 65-75\% has advanced and unresectable disease. Up to half of patients with NSCLC develop metastases at the time of the initial diagnosis, and more patients eventually experience metastases in the course of their disease. KRAS and EGFR mutation status has been analyzed in primary tumors in the majority of the current studies, but it has been demonstrated that lung cancers are 


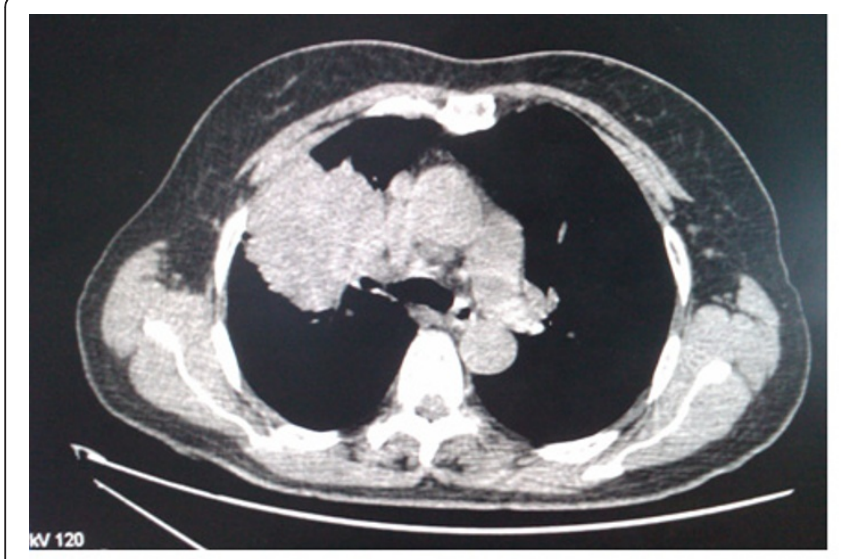

Before

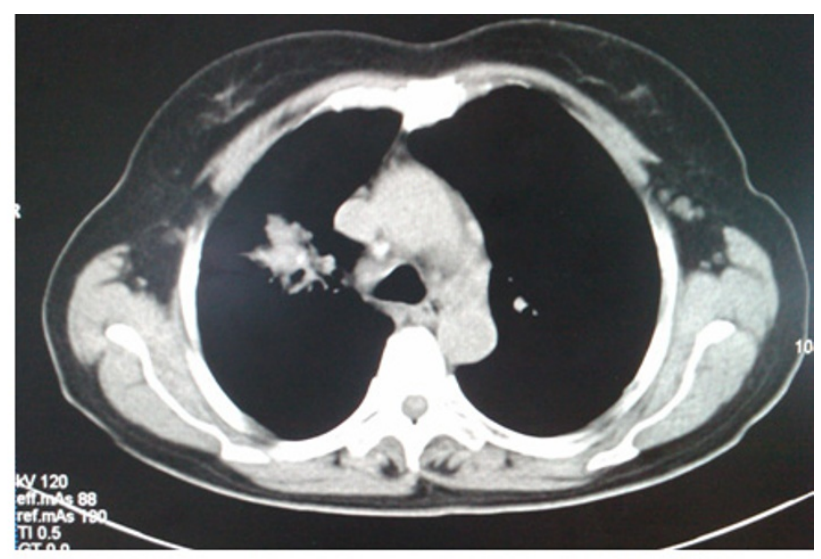

After

Figure 1 Case 21 showed that the sizes of both the primary tumor and the mediastinal lymph nodes were found to shrink after gefitinib therapy when examined by thorax CT scan.

often heterogeneous at the molecular level, even within the same tumor. In addition, molecular characteristics may differ between primary tumor and metastases. The classical model for metastatic process suggests that most cells of a given primary tumor have low metastatic potential and only a few cells acquire enough somatic mutations to become metastatic [28]. Consequently, it is of primary importance to verify the degree of correlation between primary tumor and corresponding metastases with regard to KRAS and EGFR mutation status in order to select patients who will be most likely to benefit from the treatment with TKI.

In this study we assessed KRAS and EGFR mutation status in 80 pairs of NSCLC primary tumors and their corresponding local lymph node metastases to evaluate whether KRAS and EGFR mutation status changed during disease progression. We found that tumors metastasized to the lymph nodes did not always show the same gene status as their primary compartments. In our study, the discordance in KRAS and EGFR gene status was $7.5 \%(6 / 80)$ and $8.75 \%(7 / 80)$, respectively. To our knowledge, there have been several recent similar studies in western countries. For example, Kalikaki et al. reported that the discordance in KRAS and EGFR gene status between primary tumors and corresponding metastases was $24 \%$ and $28 \%$ in 25 patients with NSCLC, respectively [24]. Schmid et al. reported that the KRAS and EGFR gene status in primary tumors and

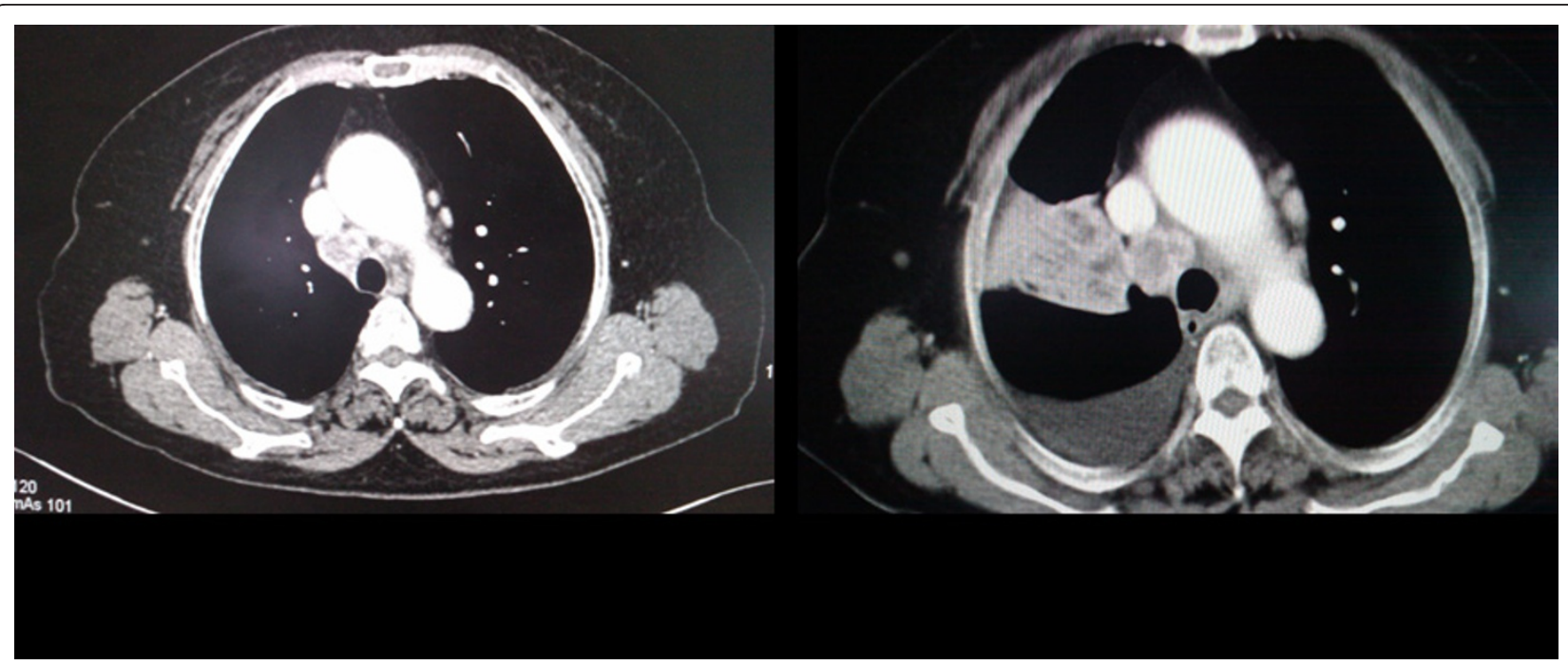

Figure 2 Case 3 showed volume increase of primary tumor and obvious hydrothorax after gefitinib therapy, as determined by thorax CT scan. 
lymph node metastases were discordant in $25(26 \%)$ and 6 (6.25\%) patients among 96 patients, respectively [26]. Monaco et al. compared 40 pairs of primary lung tumors with their metastases and found nine cases $(22.5 \%)$ with a discordant KRAS status [21]. More recently, Cortot et al. performed mutant-enriched PCR (ME-PCR) to analyze KRAS gene status in primary tumors and their matched metastases. They found that the use of ME-PCR allowed a resolution of the discordance in 3 of the 6 cases by demonstrating the presence of low levels of mutant KRAS in lesions that were found negative by direct sequencing. Their data suggests that some gene discordance could be resolved by using techniques with increased sensitivity and that highly sensitive tools are required to identify biomarkers [29]. The difference between our findings with low discordant rate and those earlier studies might be due to different ethnic background of the patients studied. In western countries, KRAS mutation rate is high in NSCLC patients, especially in those with adenocarcinoma (30\%$50 \%)$, but $E G F R$ mutation rate is low (3\%-8\%). However, Asian patients with NSCLC harbor more EGFR mutations (30\%-60\%) and fewer KRAS mutation (4\%-24\%) than western patients [30-37]. Given that there are obvious genetic differences between somatic mutations in KRAS and $E G F R$ genes in patients from Asia and western countries, it is very likely that changes of the mutation status during disease progression are different. Because relevant data about Chinese or Asian was not searched, further study should be performed to disclose the molecular mechanism.

Majority of the discordant cases in our study showed KRAS and EGFR mutations in the metastatic tumors rather than in their corresponding primary tumors (Table 2). This result suggests that the gene mutation status may change during metastases after diagnosis of the primary tumors. Although the molecular basis for this disparity is unclear, this information still has potential important clinical implications. This biological phenomenon of discordant gene mutations could partially account for the fact that some advanced NSCLC patients with apparent wild-type EGFR respond to EGFR TKI and other patients with well-known EGFR TKI-sensitive mutations in their primary tumors failed to respond to EGFR TKI. It is interesting that in our study we observed one case with delL747-P753 in mediastinal lymph nodes metastases showing progressive disease after gefitinib therapy. No EGFR mutation was found in its paired primary tumor. To our knowledge, this is the first study of the relationship between gene mutational status in both primary tumor and corresponding metastases and TKI responsiveness.

Moreover, several previous studies assessing the KRAS mutation status in primary tumors have suggested that KRAS mutation is uncommon in squamous cell carcinomas. Our data showed that the KRAS mutations were detected in the primary tumor of one adenocarcinoma and also in six metastatic tumors (five squamous cell carcinomas and one adenocacinoma), consistent with those previous reports. This result also suggests that the KRAS mutations might play an important role during metastases of NSCLC, especially squamous cell carcinomas.

Neoadjuvant or presurgical therapy is a novel therapeutic strategy that is now being investigated in the treatment of NSCLC. In part predicated on the success of this paradigm in other malignancies (such as colorectal, pancreatic, and urothelial cancers), presurgical therapy has the potential to provide real-time clinical feedback on the responsiveness of the patient's overall tumor burden to a given systemic therapy before committing the patient to what could be a highly morbid surgical procedure. Other potential benefits of this approach include local tumor down-staging, which may make subsequent surgical extirpation less morbid. In the case of locally advanced NSCLC, presurgical therapy may eliminate micrometastatic disease at its earliest stage, thus diminishing the risk of metastatic progression postoperatively. With the development and implementation of molecular targeted therapies that can meaningfully affect the biology of both primary tumors and metastases, the practice has largely been extended into the era of targeted therapy. In our study among five patients with EGFR TKI-sensitive mutations in mediastinal lymph node metastases, there were four patients who showed tumor regression in response to EGFR TKI and underwent surgery. These responses included dimension reductions in both primary tumors and mediastinal lymph nodes, suggesting tumor down-staging. Therefore, it is intriguing to consider the utilization of targeted therapies as an adjunct to make the "unresectable" become resectable. Neoadjuvant target therapy for NSCLC could potentially become a new treatment option for locally advanced and metastatic disease. On the other hand, we should not ignore the possibility that gene mutation status of primary tumors is different from that of their metastases when neoadjuvant target therapy is considered. If discordance between primary tumors and metastases is not evaluated before therapy, the patients may not benefit from the targeted therapies. Taken together, we propose that biopsies of both primary tumors and metastatic tumors of patients with advanced NSCLC, though difficult to obtain, should be pursued to ascertain the mutation status of key genes. This will allow clinicians to better understand gene mutation status and the biology of patient tumors, so that better treatment options can be selected based on tumor responsiveness to those available targeted therapies such as EGFR TKI. 


\section{Conclusions}

In summary, the substantial discordance of KRAS and EGFR mutation status between primary tumors and metastatic tumors may have therapeutic implications for EGFR-targeted therapy strategy. For NSCLC patients with metastases, determining the KRAS and EGFR mutation status in both primary and metastatic tumors may be critical for making meaningful decisions regarding the appropriate use of targeted therapies.

\section{Author details}

'Department of Pathology, Tianjin Medical University Cancer Institute and Hospital; Tianjin 300060, China. ${ }^{2}$ Department of Thoracic Surgery, Tianjin Medical University Cancer Institute and Hospital; Tianjin 300060, China. ${ }^{3}$ Key Laboratory of Cancer Prevention and Therapy, Tianjin 300060, China. ${ }^{4}$ Tianjin Diagnosis and Therapy Center of Lung Cancer, Tianjin 300060, China.

\section{Authors' contributions}

ZZ, CW and BS designed the study; LS and QZ performed experiments; LS and $\mathrm{HL}$ analyzed data and prepared the Tables and Figures; LS and BS drafted the manuscript. All authors have read and approved the final manuscript.

\section{Competing interests}

The authors declare that they have no competing interests.

Received: 27 January 2011 Accepted: 17 March 2011

Published: 17 March 2011

\section{References}

1. Molina JR, Yang P, Cassivi SD, Schild SE, Adjei AA: Non-small cell lung cancer: epidemiology, risk factors, treatment, and survivorship. Mayo Clin Proc 2008, 83:584-594.

2. Jemal A, Siegel R, Ward E, Hao Y, Xu J, Thun MJ: Cancer statistics, 2009. CA Cancer J Clin 2009, 59:225-249.

3. Hansen HH: Treatment of advanced non-small cell lung cancer. BMJ 2002, 325:452-453.

4. Hirsch FR, Varella-Garcia M, Bunn PA Jr, Di Maria MV, Veve R, Bremmes RM, Baron AE, Zeng C, Franklin WA: Epidermal growth factor receptor in nonsmall-cell lung carcinomas: correlation between gene copy number and protein expression and impact on prognosis. J Clin Oncol 2003, 21:3798-3807.

5. Paez JG, Janne PA, Lee JC, Tracy S, Greulich H, Gabriel S, Herman P, Kaye FJ, Lindeman N, Boggon TJ, et al: EGFR mutations in lung cancer: correlation with clinical response to gefitinib therapy. Science 2004, 304:1497-1500.

6. Pao W, Miller V, Zakowski M, Doherty J, Politi K, Sarkaria I, Singh B, Heelan R, Rusch V, Fulton $L$, et al: EGF receptor gene mutations are common in lung cancers from "never smokers" and are associated with sensitivity of tumors to gefitinib and erlotinib. Proc Natl Acad Sci USA 2004, 101:13306-13311.

7. Pirker R, Minar W, Filipits M: Integrating epidermal growth factor receptortargeted therapies into platinum-based chemotherapy regimens for newly diagnosed non-small-cell lung cancer. Clin Lung Cancer 2008, 9(Suppl 3):S109-115.

8. Pirker R, Filipits M: Targeted therapies in lung cancer. Curr Pharm Des 2009, 15:188-206.

9. Lynch TJ, Bell DW, Sordella R, Gurubhagavatula S, Okimoto RA, Brannigan BW, Harris PL, Haserlat SM, Supko JG, Haluska FG, et al: Activating mutations in the epidermal growth factor receptor underlying responsiveness of non-small-cell lung cancer to gefitinib. $N$ Engl I Med 2004, 350:2129-2139.

10. Fukuoka M, Yano S, Giaccone G, Tamura T, Nakagawa K, Douillard JY, Nishiwaki Y, Vansteenkiste J, Kudoh S, Rischin D, et al: Multi-institutional randomized phase II trial of gefitinib for previously treated patients with advanced non-small-cell lung cancer (The IDEAL 1 Trial) [corrected]. J Clin Oncol 2003, 21:2237-2246.
11. Kris MG, Natale RB, Herbst RS, Lynch TJ Jr, Prager D, Belani CP, Schiller JH, Kelly K, Spiridonidis H, Sandler A, et al: Efficacy of gefitinib, an inhibitor of the epidermal growth factor receptor tyrosine kinase, in symptomatic patients with non-small cell lung cancer: a randomized trial. Jama 2003, 290:2149-2158.

12. Eberhard DA, Johnson BE, Amler LC, Goddard AD, Heldens SL, Herbst RS, Ince $\mathrm{WL}$, Janne PA, Januario $\mathrm{T}$, Johnson $\mathrm{DH}$, et al: Mutations in the epidermal growth factor receptor and in KRAS are predictive and prognostic indicators in patients with non-small-cell lung cancer treated with chemotherapy alone and in combination with erlotinib. J Clin Oncol 2005, 23:5900-5909.

13. Qin BM, Chen X, Zhu JD, Pei DQ: Identification of EGFR kinase domain mutations among lung cancer patients in China: implication for targeted cancer therapy. Cell Res 2005, 15:212-217.

14. Zhang $X T$, Li LY, Mu XL, Cui QC, Chang XY, Song W, Wang SL, Wang MZ, Zhong $W$, Zhang $L$ : The EGFR mutation and its correlation with response of gefitinib in previously treated Chinese patients with advanced nonsmall-cell lung cancer. Ann Oncol 2005, 16:1334-1342.

15. Massarelli E, Varella-Garcia M, Tang X, Xavier AC, Ozburn NC, Liu DD, Bekele BN, Herbst RS, Wistuba II: KRAS mutation is an important predictor of resistance to therapy with epidermal growth factor receptor tyrosine kinase inhibitors in non-small-cell lung cancer. Clin Cancer Res 2007, 13:2890-2896.

16. Perry MC, Ihde DC, Herndon JE, Grossbard ML, Grethein SJ, Atkins JN, Vokes EE, Green MR: Paclitaxel/ifosfamide or navelbine/ifosfamide chemotherapy for advanced non-small cell lung cancer: CALGB 9532. Lung cancer 2000, 28(1):63-68.

17. Yang P, Allen MS, Aubry MC, Wampfler JA, Marks RS, Edell ES, Thibodeau S, Adjei AA, Jett J, Deschamps C: Clinical features of 5,628 primary lung cancer patients: experience at Mayo Clinic from 1997 to 2003. Chest 2005, 128:452-462.

18. Petersen S, Aninat-Meyer M, Schluns K, Gellert K, Dietel M, Petersen I: Chromosomal alterations in the clonal evolution to the metastatic stage of squamous cell carcinomas of the lung. Br J Cancer 2000, 82:65-73.

19. Ubagai T, Matsuura S, Tauchi H, Itou K, Komatsu K: Comparative genomic hybridization analysis suggests a gain of chromosome $7 p$ associated with lymph node metastases in non-small cell lung cancer. Oncol Rep 2001, 8:83-88.

20. Taniguchi K, Okami J, Kodama K, Higashiyama M, Kato K: Intratumor heterogeneity of epidermal growth factor receptor mutations in lung cancer and its correlation to the response to gefitinib. Cancer Sci 2008, 99:929-935.

21. Monaco SE, Nikiforova MN, Cieply K, Teot LA, Khalbuss WE, Dacic S: A comparison of EGFR and KRAS status in primary lung carcinoma and matched metastases. Hum Pathol 2010, 41:94-102.

22. Italiano A, Vandenbos FB, Otto J, Mouroux J, Fontaine D, Marcy PY, Cardot N, Thyss A, Pedeutour F: Comparison of the epidermal growth factor receptor gene and protein in primary non-small-cell-lung cancer and metastatic sites: implications for treatment with EGFR-inhibitors. Ann Oncol 2006, 17:981-985.

23. Bozzetti C, Tiseo M, Lagrasta C, Nizzoli R, Guazzi A, Leonardi F, Gasparro D, Spiritelli E, Rusca M, Carbognani $P$, et al: Comparison between epidermal growth factor receptor (EGFR) gene expression in primary non-small cell lung cancer (NSCLC) and in fine-needle aspirates from distant metastatic sites. J Thorac Oncol 2008, 3:18-22.

24. Kalikaki A, Koutsopoulos A, Trypaki M, Souglakos J, Stathopoulos E, Georgoulias V, Mavroudis D, Voutsina A: Comparison of EGFR and K-RAS gene status between primary tumours and corresponding metastases in NSCLC. Br J Cancer 2008, 99:923-929.

25. Park S, Holmes-Tisch AJ, Cho EY, Shim YM, Kim J, Kim HS, Lee J, Park YH, Ahn JS, Park K, et al: Discordance of molecular biomarkers associated with epidermal growth factor receptor pathway between primary tumors and lymph node metastases in non-small cell lung cancer. $J$ Thorac Oncol 2009, 4:809-815.

26. Schmid K, Oehl N, Wrba F, Pirker R, Pirker C, Filipits M: EGFR/KRAS/BRAF mutations in primary lung adenocarcinomas and corresponding locoregional lymph node metastases. Clin Cancer Res 2009, 15:4554-4560.

27. Eisenhauer EA, Therasse P, Bogaerts J, Schwartz LH, Sargent D, Ford R, Dancey J, Arbuck S, Gwyther S, Mooney M, et al: New response evaluation criteria in solid tumours: revised RECIST guideline (version 1.1). Eur J Cancer 2009, 45:228-247. 
28. Bernards R, Weinberg RA: A progression puzzle. Nature 2002, 418:823.

29. Cortot AB, Italiano A, Burel-Vandenbos F, Martel-Planche G, Hainaut P: KRAS mutation status in primary nonsmall cell lung cancer and matched metastases. Cancer 2010, 116:2682-2687.

30. Noda N, Matsuzoe D, Konno T, Kawahara K, Yamashita Y, Shirakusa T: K-ras gene mutations in non-small cell lung cancer in Japanese. Oncol Rep 2001, 8:889-892

31. Kosaka T, Yatabe Y, Endoh H, Kuwano H, Takahashi T, Mitsudomi T: Mutations of the epidermal growth factor receptor gene in lung cancer: biological and clinical implications. Cancer Res 2004, 64:8919-8923.

32. Pao W, Wang TY, Riely GJ, Miller VA, Pan Q, Ladanyi M, Zakowski MF, Heelan RT, Kris MG, Varmus HE: KRAS mutations and primary resistance of lung adenocarcinomas to gefitinib or erlotinib. PLoS Med 2005, 2:e17.

33. Suzuki M, Shigematsu H, Hiroshima K, lizasa T, Nakatani Y, Minna JD, Gazdar AF, Fujisawa T: Epidermal growth factor receptor expression status in lung cancer correlates with its mutation. Hum Pathol 2005, 36:1127-1134.

34. Tam IY, Chung LP, Suen WS, Wang E, Wong MC, Ho KK, Lam WK, Chiu SW, Girard L, Minna JD, et al: Distinct epidermal growth factor receptor and KRAS mutation patterns in non-small cell lung cancer patients with different tobacco exposure and clinicopathologic features. Clin Cancer Res 2006, 12:1647-1653.

35. Bae NC, Chae MH, Lee MH, Kim KM, Lee EB, Kim CH, Park TI, Han SB, Jheon S, Jung TH, Park JY: EGFR, ERBB2, and KRAS mutations in Korean non-small cell lung cancer patients. Cancer Genet Cytogenet 2007, 173:107-113.

36. Marks JL, Broderick S, Zhou Q, Chitale D, Li AR, Zakowski MF, Kris MG, Rusch WW, Azzoli CG, Seshan VE, et al: Prognostic and therapeutic implications of EGFR and KRAS mutations in resected lung adenocarcinoma. J Thorac Oncol 2008, 3:111-116.

37. Wu CC, Hsu HY, Liu HP, Chang JW, Chen YT, Hsieh WY, Hsieh JJ, Hsieh MS, Chen YR, Huang SF: Reversed mutation rates of KRAS and EGFR genes in adenocarcinoma of the lung in Taiwan and their implications. Cancer 2008, 113:3199-3208.

doi:10.1186/1756-9966-30-30

Cite this article as: Sun et al: Comparison of KRAS and EGFR gene status between primary non-small cell lung cancer and local lymph node metastases: implications for clinical practice. Journal of

Experimental \& Clinical Cancer Research 2011 30:30.

\section{Submit your next manuscript to BioMed Central} and take full advantage of:

- Convenient online submission

- Thorough peer review

- No space constraints or color figure charges

- Immediate publication on acceptance

- Inclusion in PubMed, CAS, Scopus and Google Scholar

- Research which is freely available for redistribution

Submit your manuscript at www.biomedcentral.com/submit
C Biomed Central 